\title{
Proteases HtrA and HtrB for a-amylase secreted from Bacillus subtilis in secretion stress
}

\author{
Shaomin $\mathrm{Yan}^{1} \cdot$ Guang $\mathrm{Wu}^{1}$ (D) \\ Received: 19 January 2019 /Revised: 22 February 2019 / Accepted: 25 February 2019/Published online: 18 April 2019 \\ (C) The Author(s) 2019
}

\begin{abstract}
HtrA and HtrB are two important proteases across species. In biotechnological industries, they are related to degradation of secreted heterologous proteins from bacteria, especially in the case of overproduction of $\alpha$-amylases in Bacillus subtilis. Induction of HtrA and HtrB synthesis follows the overproduction of $\alpha$-amylases in $B$. subtilis. This is different from the order usually observed in B. subtilis, i.e., the production of proteases is prior to the secretion of proteins. This discrepancy suggests three possibilities: (i) HtrA and HtrB are constantly synthesized from the end of the exponential phase, and then are synthesized more abundantly due to secretion stress; (ii) There is a hysteresis mechanism that holds HtrA and HtrB back from their large amount of secretion before the overproduction of $\alpha$-amylases; (iii) Heterologous amylases could be a stress to $B$. subtilis leading to a general response to stress. In this review, we analyze the literature to explore these three possibilities. The first possibility is attributed to the regulatory pathway of CssR-CssS. The second possibility is because sigma factor $\sigma^{\mathrm{D}}$ plays a role in the overproduction of $\alpha$-amylases and is subpopulation dependent with the switch between "ON" and "OFF" states that is fundamental for a bistable system and a hysteresis mechanism. Thus, sigma factor $\sigma^{\mathrm{D}}$ helps to hold HtrA and HtrB back from massive secretion before the overproduction of $\alpha$-amylases. The third possibility is that several sigma factors promote the secretion of proteases at the end of the exponential phase of growth under the condition that heterologous amylases are considered as a stress.
\end{abstract}

Keywords $\alpha$-Amylase $\cdot$ B. subtilis $\cdot \mathrm{HtrA} \cdot$ Secretion stress $\cdot$ Sigma factor

\section{Introduction}

Secretion stress usually refers to the high-level $\alpha$-amylase production in Bacillus subtilis (Lulko et al., 2007; Ploss et al., 2016) although it was also observed in the overproduction of Sec-secreted proteins in Streptomyces lividans (Gullón et al., 2012; Vicente et al., 2016). Secretion stress is largely dependent upon the nature of the secreted protein that is overproduced (Westers et al., 2006). Secretion stress goes through three different systems: Sec secretion system, CssRCssS regulatory system, and HtrA and HtrB proteases. Sec system is a component in type II secretion system and is involved in secretion stress (Yan and $\mathrm{Wu}, 2017)$. CssR-CssS

Guang $\mathrm{Wu}$

hongguanglishibahao@gxas.cn

1 State Key Laboratory of Non-Food Biomass and Enzyme Technology, National Engineering Research Center for Non-Food Biorefinery, Guangxi Key Laboratory of Bio-refinery, Guangxi Academy of Sciences, 98 Daling Road, Nanning 530007, Guangxi, China stands for controlling regulator and sensor of secretion stress, and is a two-component system (Hyyryläinen et al., 2001) belonging to class $\mathrm{V}$ heat-inducible genes (Darmon et al., 2002). HtrA and HtrB are two membrane-bound proteases that were initially termed as membrane-bound HtrA-like proteases YkdA and YvtA (Noone et al., 2000; Tjalsma et al., 2000).

In this review, we are particularly interested in $\mathrm{HtrA}$ and HtrB (Fig. 1), because they degrade $\alpha$-amylases (Darmon et al., 2002; Ploss et al., 2016) that are heterogeneously expressed and secreted from $B$. subtilis. At first glance, the pathway of secretion stress looks simple; however, its regulation includes not only the auto-regulation of $\operatorname{css} R S$ operon but also the cross-regulation (pink colored items in Fig. 1). This auto-regulation is subject to the level of CssR and CssS, absence of HtrA or HtrB, heat, and secretory proteins (Darmon et al., 2002; Noone et al., 2000, 2001). HtrA and HtrB have the reciprocal cross-regulation of their own genes and a negative auto-regulation of $h t r B$ (green-colored items in Fig. 1) (Noone et al., 2001). The regulation of HtrA and HtrB, especially for HtrA, is complicated, and has been the subject of 
Fig. 1 Secretion stress due to overproduction of $\alpha$-amylases in B. subtilis and induction of HtrA and HtrB synthesis with various stresses and regulators. An arrow indicates a positive regulation, an ending symbol indicates a negative regulation, and the line width is proportional to regulatory effect

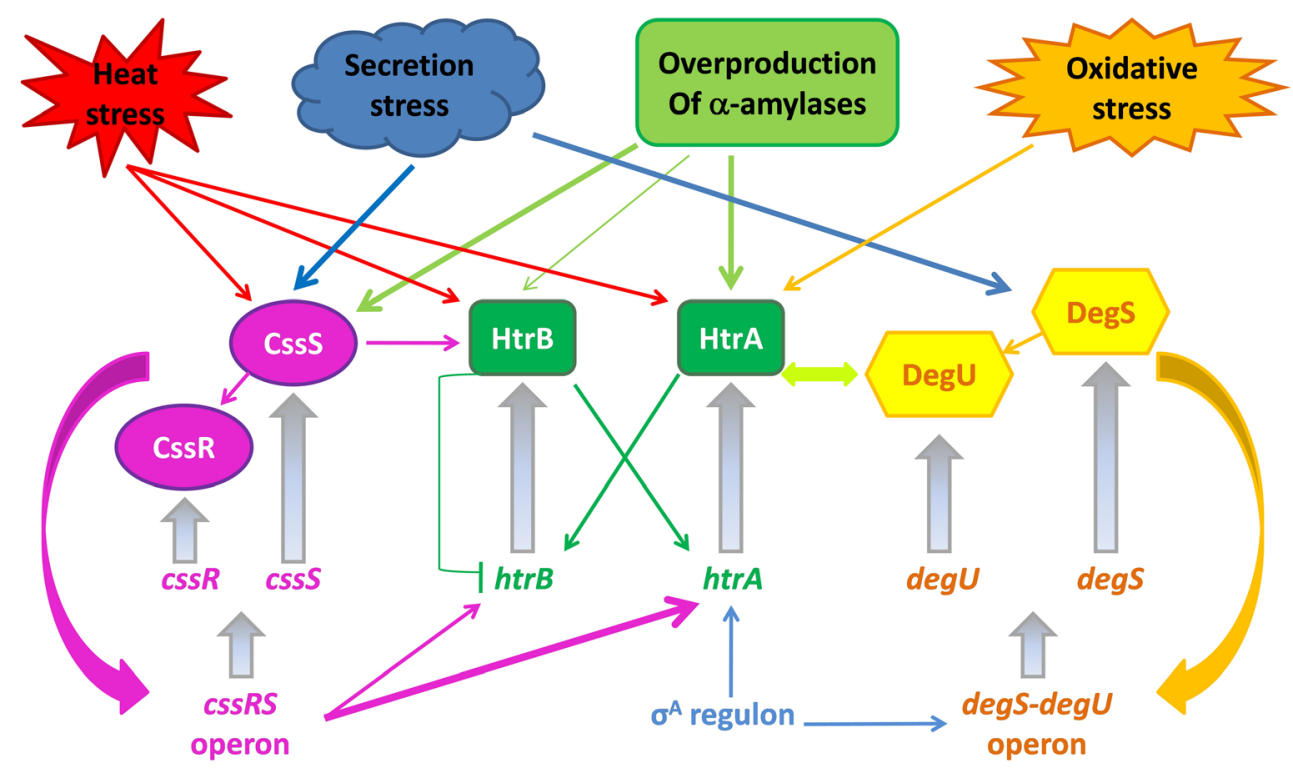

reviews with their three-dimensional structure (Clausen et al., 2011; Hansen and Hilgenfeld, 2013; Pallen and Wren, 1997; Singh et al., 2011).

For HtrA, our knowledge largely comes from the studies in Gram-negative bacteria, whose proteases are better characterized than their counterparts in Gram-positive bacteria. For example, DegP from Escherichia coli is a model protease of the HtrA family. Two trimeric HtrA rings form a hexamer in the inactive state (Krojer et al., 2002), while the hexamers are dissociated into trimers in the active state (Krojer et al., 2008). By contrast, our knowledge on HtrA homologs in Grampositive bacteria is limited.

The well-known secretion stress is very specific because the induction of HtrA and HtrB synthesis comes from the overproduction of $\alpha$-amylases in B. subtilis (light greencolored rectangle on the top of Fig. 1). Hence, the overproduction of $\alpha$-amylases occurs prior to the synthesis of HtrA and HtrB. This is interesting, because the synthesis of proteases, including HtrA and HtrB (Gullón et al., 2012), often occurs at the end of the exponential phase of growth in Bacillus (Margot and Karamata, 1996; Priest, 1977; Shen et al., 2005), especially when a large amount of proteases is needed (Liu et al., 2005) (solid blue line in Fig. 2). On the other hand, most secretion of proteins in B. subtilis occurs at the beginning of the stationary phase of growth (Bolhuis et al., 1998; Herbort et al., 1999). Generally, the activity of secretion of proteins is quite low during exponential phase but increases substantially at the onset of stationary phase (Priest, 1977). Moreover, several components of Sec secretion system, through which $\alpha$-amylases are secreted, reach their maximum expression either at the end of exponential growth phase (Herbort et al., 1999) or at the early post-exponential phase (Bolhuis et al., 1998) in B. subtilis (pink line in Fig. 2).
This discrepancy highlights a hysteresis feature (dashed blue line in Fig. 2) suggesting three possibilities: (i) HtrA and HtrB are constantly synthesized from the end of the exponential phase, and are then synthesized more abundantly due to secretion stress; (ii) There is a hysteresis mechanism that holds HtrA and HtrB back from a large amount of secretion before the overproduction of $\alpha$-amylases; (iii) Heterologous amylases could be a stress to $B$. subtilis leading to a general response to stress because they can induce HtrA and HtrB synthesis at the transition phase of the growth cycle (Noone et al., 2001) or at the late exponential phase and the stationary-growth phase (Lulko et al., 2007). Hence, the aim of this review is designed to explore these possibilities by reviewing literature.

\section{Induction of synthesis of HtrA and HtrB by CssR-CssS due to overproduction}

HtrA and HtrB stand for high-temperature requirement A and B (Darmon et al., 2002), and their expression is induced by heat stress and $\alpha$-amylase overproduction (Noone et al., 2000, 2001), but CssR-CssS controls their induction (lower left side in Fig. 1). However, the response of both HtrA and HtrB to CssR-CssS reveals a difference, in that HtrA is more sensitive to CssR-CssS (Hyyryläinen et al., 2001). As HtrA and HtrB are inducible by $\alpha$-amylase overproduction, our question raised here is which one induces the synthesis of HtrA and HtrB: the misfolded $\alpha$-amylases or the quantity of overproduced $\alpha$-amylases? It seems that misfolded $\alpha$ amylases might not be entirely related to the overproduction of $\alpha$-amylases. 
Fig. 2 Production of $\alpha$-amylases and induction of HtrA and $\mathrm{HtrB}$ synthesis along the time course with respect to possible hysteresis

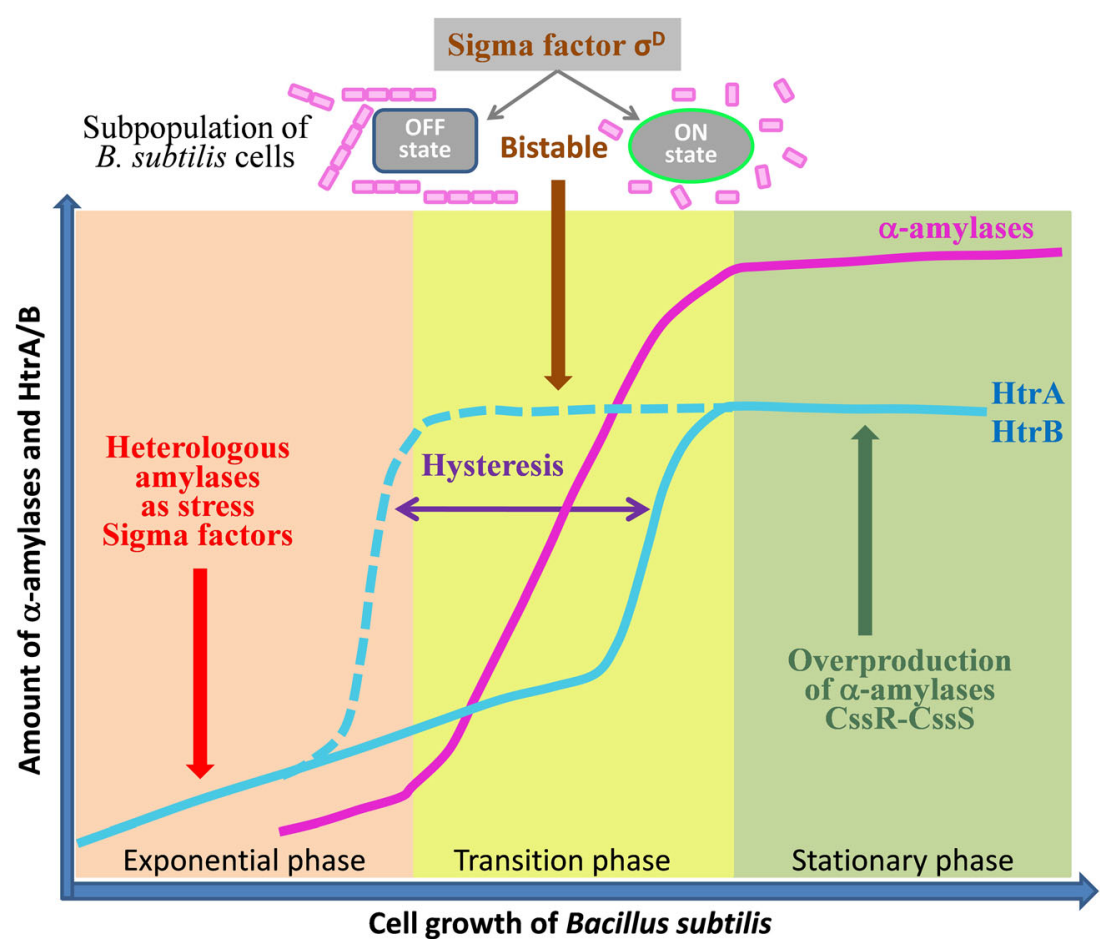

\section{CssS as a sensor}

As a bicomponent regulatory system, CssR and CssS work as the response regulator CssR and the membrane-embedded sensor kinase CssS. The CssS detects misfolded proteins at the membrane-cell wall interface and monitors the overproduction of $\alpha$-amylase (AmyQ), and in return controls the synthesis of extracytoplasmic proteases. The activation of CssR goes through phosphorylation (Hyyryläinen et al., 2001). However, the signal to induce htrA and $h t r B$ expression is probably not misfolded cytosolic proteins, because puromycin is unable to induce their expression (Darmon et al., 2002; Noone et al., 2000). Still, the induction of $h t r B$ is CssS dependent for secretion stress whereas the induction of $h t r A$ and $h$ trB is CssS dependent for heat stress (left side in Fig. 1). Actually, $\operatorname{css} R S$ responds to high levels of $\alpha$-amylases (Darmon et al., 2002).

HtrA is not the only protease whose synthesis is controlled by the CssR-CssS system at the membrane-cell wall interface (Hyyryläinen et al., 2001), because the results from $\operatorname{css} S$ and htrA mutant strains suggested that CssR-CssS also controls at least another protease (Darmon et al., 2002). On the other hand, CssR-CssS does not regulate all proteases. For example, a membrane-cell wall interface serine protease CWBP52 in B. subtilis is beyond its regulation (Margot and Karamata, 1996). In fact, neither the nature of heterologous amylases nor their secretion was sufficient for $h$ trA and $h$ tr $B$ induction. Their induction includes (i) the secretion load such as the total number of proteins and the amount of each protein being processed and/or secreted, (ii) the stage of protein maturation, and (iii) the degradation level of aberrant protein (Noone et al., 2001). As the misfolded $\alpha$-amylases may not be directly linked with the overproduction of $\alpha$-amylases, CssS serves as a sensor to detect the overproduction of $\alpha$-amylases.

As a protease induced by heat shock (red-colored items in Fig. 1), HtrA belongs to serine proteases and exists widely across species (Pallen and Wren, 1997). The study on extracellular proteome of B. subtilis demonstrated two types of HtrA (Antelmann et al., 2003): membrane-bound HtrA and soluble HtrA. The former one has an $\mathrm{N}$-terminal membrane anchor whereas the transmembrane region is cleaved in the latter one. The secretion mechanism for HtrA in B. subtilis is similar to the human HtrA2/Omi protein (Vande Walle et al., 2008), i.e., the full-length HtrA is firstly transported and integrated into cytoplasmic membrane, then is processed into a soluble form with activity, and finally is released into the extracytoplasmic space.

\section{HtrA as chaperone}

Two locations of HtrA in B. subtilis imply its two functions (Antelmann et al., 2003). In addition to the protease activity, HtrA acts as a molecular chaperone when present in the culture supernatant (Antelmann et al., 2003). Also, HtrA works as a chaperone at lower temperatures but as a protease at high temperature (Spiess et al., 1999). In such a case, HtrA would have a similar function as DnaK and 
GroEL to prevent the accumulation of unfolded proteins during stress (Wegele et al., 2004). The overproduction of $\alpha$-amylases leads to a stimulatory effect on the genes for the general stress proteins, DnaK and GroEL (Lulko et al., 2007). Therefore, HtrA, that is synthesized at the end of the exponential phase, could function as a chaperone to deal with misfolded $\alpha$-amylases.

Furthermore, the study on extracellular proteome of B. subtilis showed that only HtrA and YqxI had changed in response to secretion stress (Antelmann et al., 2003). Under the condition of high-level AmyQ production, an augmentation of transcription can be found in htrA but not in yqxI. The amount of extracellular HtrA increases at the transcriptional level, whereas that of YqxI changes at post-transcriptional level and is HtrA dependent. However, no significant change was found in extracellular amount of HtrB in B. subtilis in response to secretion stress (Antelmann et al., 2003). Therefore, there are substantial amounts of HtrA near the extracytoplasmic membrane surface of $B$. subtilis under the condition of secretion stress. This suggests that HtrA in B. subtilis may serve as a detector sensing secretion stress like CssS (Hyyryläinen et al., 2001).

Crystallographic study illustrates the structure of the PDZ domain of $\mathrm{HtrA}$ that contains trimeric rings forming flexible sidewalls with a central cavity. The PDZ domain is considered necessary for proteolytic function and/or chaperone-like function because it binds to its substrate and brings it into the cavity (Krojer et al., 2002). Intriguingly, the HtrA from E. coli has two PDZ domains whereas the HtrA from B. subtilis has only one PDZ domain. This implicates that a single conserved PDZ domain in B. subtilis $\mathrm{HtrA}$ is sufficient for its dual functions (Antelmann et al., 2003). However, multiple PDZ domains in the HtrA from Thermotoga maritima appear dispensable to perform both proteolytic and chaperone-like functions (Kim and Kim, 2002).

\section{HtrA activation}

The main mechanism for activating the HtrA proteases is based on allostery as well as temperature (Figaj et al., 2014). Binding of an appropriate allosteric peptide or a substrate leads to structural rearrangement of the protein and consequently to increased activity of the enzyme (Hansen and Hilgenfeld, 2013; Löwer et al., 2008). However, additional mechanisms exist. For example, the HtrA (DegP) in E. coli may be regulated by reversible reduction/oxidation of the S-S bridge (Figaj et al., 2014; Koper et al., 2015) located in the regulatory loop LA (Skorko-Glonek et al., 2006).

The review in this section supports the possibility that HtrA and HtrB may be constantly synthesized from the end of the exponential phase, and then synthesized more abundantly due to secretion stress through CssR-CssS regulatory pathway.

\section{Induction of synthesis of HtrA and HtrB by sigma factor $\sigma^{D}$}

As HtrA is independent of CssR in B. subtilis (Lulko et al., 2007), our question raised here is whether $B$. subtilis has a secondary mechanism to induce the synthesis of HtrA and HtrB.

Sigma factor $\sigma^{\mathrm{D}}$ is expressed during vegetative growth and controls the expression of genes during exponential growth and the early stationary phase (Marquez et al., 1990). Sigma factor $\sigma^{\mathrm{D}}$ is related to the gene expression of flagellum and motility, whose upregulation is an adaptive response in B. subtilis (Helmann et al., 1988; Marquez et al., 1990). Upon AmyQ overproduction, motility-specific $\left(\sigma^{\mathrm{D}}\right.$-dependent) transcripts were upregulated (Lulko et al., 2007). Some flagellar genes can only express in a subpopulation of B. subtilis (Kearns and Losick, 2005), whose population bifurcates into two types (top part in Fig. 2). During exponential growth phase, $B$. subtilis cells can appear either single motile individuals or sessile cell chains, where the cells join end-toend (Mukherjee and Kearns, 2014). This population heterogeneity is under the control of sigma factor $\sigma^{\mathrm{D}}$ (Chen et al., 2008; Helmann et al., 1988; Kearns and Losick, 2005; Marquez et al., 1990).

\section{Evidence from $\sigma^{\mathrm{D}}$}

In biotechnological settings, a flagellum gene, hag, is knocked out from B. licheniformis BL9 and BL10 in order to increase the yield of $\alpha$-amylase (Chen et al., 2015) and nattokinase (Wei et al., 2015). Also hag can serve as a reporter to study environmental effects on $\sigma^{\mathrm{D}}$-dependent gene expression (Lulko et al., 2007; Mirel and Chamberlin, 1989). At the "ON" state for sigma factor $\sigma^{\mathrm{D}}$ activity, B. subtilis can express hag that completes flagellum assembly, and $l y t F$ that is a peptidoglycan endopeptidase (Yamamoto et al., 2008; Margot et al., 1999) and separates the cells from chains. At the "OFF" state for sigma factor $\sigma^{\mathrm{D}}$ activity, neither hag nor lyt $F$ is expressed in B. subtilis so the cells form non-motile chains (Chen et al., 2008). Therefore, the activity of sigma factor $\sigma^{\mathrm{D}}$ decides the fate of individual cells in each subpopulation (Mukherjee and Kearns, 2014). The strains commonly used in laboratories are biased towards the OFF state and grow predominantly as long chains, whereas the ancestral strain is biased towards the ON state and grow predominantly as motile individuals (Kearns and Losick, 2005). As a result, the Bacillus strain, whose hag is knocked out, is highly likely to belong to the OFF state. Our question raised here is what is the population heterogeneity for $B$. subtilis-producing $\alpha$-amylase? Consequently, does the portion of $\alpha$-amylase-producing $B$. subtilis cells belong to the ON or OFF state? 


\section{Hysteresis}

Evidence suggests that there is a hysteresis mechanism that holds HtrA and HtrB back from a large amount of secretion prior to the overproduction of $\alpha$-amylases. Essentially, the hysteresis is a characteristic of bistable systems (top part in Fig. 2), where an acquired state resists to switch into another state in the absence of a history-dependent stimulus (Priest, 1977). For this reason, we can consider the ON and OFF states for sigma factor $\sigma^{\mathrm{D}}$ activity as a bistable system.

\section{Further evidence from $\sigma^{D}$}

In B. subtilis, DegU-P can activate promoter flgM (Hsueh et al., 2011), whose product FlgM inhibits sigma factor $\sigma^{\mathrm{D}}$ (Bertero et al., 1999; Caramori et al., 1996; Daughdrill et al., 1997; Sorenson et al., 2004). SwrA (swarming motility protein) may activate the fla/che operon indirectly by binding to and antagonizing a repressor, the phosphorylated form of the response regulator DegU-P (Amati et al., 2004; Mordini et al., 2013; Ogura and Tsukahara, 2012; Tsukahara and Ogura, 2008), although this protein is discontinued in gene bank for B. amyloliquefaciens FZB42, LL3, TA208, XH7, Y2, etc. For sigma factor $\sigma^{\mathrm{D}}$, its feed-forward regulation is the reason for bistability (Allmansberger, 1997; Estacio et al., 1998; Mordini et al., 2013) that could lead to the abovementioned hysteresis for HtrA and HtrB. Moreover, sigma factor $\sigma^{\mathrm{D}}$ increases during growth and reaches its maximum level at the transition point (Mirel and Chamberlin, 1989; Mirel et al., 2000), whose trend is similar to the induction of $\mathrm{HtrA}$ and $\mathrm{HtrB}$ at the transition phase of the growth cycle (Noone et al., 2001) or in the late exponential phase and the stationary-growth phase (Lulko et al., 2007). And the overproduction of $\alpha$-amylases prolongs the motile phase in B. subtilis (Lulko et al., 2007), i.e., the ON state, which could lead to replacement and competition for core RNA polymerase during stationary phase in B. subtilis (Hicks and Grossman, 1996; Ju et al., 1999; Lord et al., 1999). Furthermore, these can be connected to sporulation (Eichenberger et al., 2004), and RNA polymerases in excess could lead to deactivation of $\sigma^{\mathrm{A}}$ (middle lower part in Fig. 1) (Fujita, 2000).

To this end, the induction of synthesis of HtrA and $\mathrm{HtrB}$ is the consequence of activation of CssR-CssS by peptidoglycan recognition proteins. The layer of peptidoglycan is thicker in B. subtilis than in other bacteria (Mukherjee and Kearns, 2014). Peptidoglycan recognition proteins can depolarize the cell membrane, stop synthesizing intracellular peptidoglycan, protein, RNA, and DNA, but they can also produce hydroxyl radicals leading to bacterial death in B. subtilis (Kashyap et al., 2011). In this regard, the activity of sigma factor $\sigma^{\mathrm{D}}$ on $l y t F$, peptidoglycan endopeptidase (Margot et al., 1999; Yamamoto et al., 2008), could explain the link between HtrA and oxidation.
The review in this section explores the possibility that the synthesis of $\mathrm{Htr} \mathrm{A}$ and $\mathrm{HtrB}$ is induced by the overproduction of $\alpha$-amylases through sigma factor $\sigma^{\mathrm{D}}$, and the possibility that sigma factor $\sigma^{\mathrm{D}}$ helps to hold HtrA and HtrB back from massive secretion before the overproduction of $\alpha$-amylases that is the mechanism of hysteresis.

\section{Possible roles of other sigma factors}

Since the induction of the synthesis of HtrA and HtrB by secretion stress in $B$. subtilis occurs quite late, our question raised here is whether $B$. subtilis has other mechanisms to induce HtrA and HtrB synthesis before the secretion stress? An answer discussed above is that the induction of HtrA and $\mathrm{HtrB}$ synthesis before the secretion stress is to use $\mathrm{HtrA}$ as a chaperone. However, some studies suggested that HtrA is more likely to function as a protease rather than chaperone in B. subtilis (Margot and Karamata, 1996) and in E. coli (Chang, 2016; Ge et al., 2014).

Thus, we need to explore the third possibility, i.e., do heterologous amylases serve as a stress to $B$. subtilis? If this is so, then heterologously expressed proteins could induce the general response to stress. Truly, B. subtilis has a sophisticated regulatory system in response to various stresses and maintains its survival, for which the induction of general response proteins is the earliest response (Hecker and Völker, 2001). Well-known stresses like heat shock (Hyyryläinen et al., 2001) (left upper corner in Fig. 1) and oxidation (Kashyap et al., 2011) (right upper corner in Fig. 1) can induce HtrA in $B$. subtilis because HtrA belongs to the regulon that is linked to the response to oxidative stress in B. subtilis (Noone et al., 2000). Once again, our attention is given to sigma factors, not only because sigma factors in $B$. subtilis play crucial roles at different levels in response to stresses but also because heterologous amylases are a stress.

\section{Sigma factor $\sigma^{A}$}

At least three well-characterized classes of heat-inducible genes exist in B. subtilis, i.e., HrcA/CIRCE (Hecker et al., 1996; Zuber and Schumann, 1994), SigB (Hecker and Völker, 1998) and CtsR (Derré et al., 1999; Krüger and Hecker, 1998), and sigma factor $\sigma^{\mathrm{A}}$ (middle lower part in Fig. 1). The $\sigma^{\mathrm{A}}$ is found from purified RNA polymerase (Shorenstein and Losick, 1973) and belongs to group I sigma factor (Haldenwang, 1995; Gruber and Gross, 2003). It deals with the expression of genes responding to heat shock (Chang et al., 1994), especially when B. subtilis cells grow in rich medium (Haldenwang, 1995). In fact, the overexpression of heterologous proteins was considered as a stress to $B$. subtilis (Mogk et al., 1998) because folded or misfolded proteins can trigger the cellular stress response when their number 
increases. HrcA represses the genes encoding chaperones, but its function is influenced by chaperones, for example, $\mathrm{HrcA}$ activation needs GroE (Mogk et al., 1997). During heat stress or protein overproduction, the chaperones deal with accumulated proteins, resulting in $\mathrm{HrcA}$ inactivation. Additionally, oxidative stress indirectly induces misfolded proteins, leading to the expression of chaperone encoding genes that are regulated by CtsR (Derré et al., 1999). DegS belongs to a twocomponent regulatory system DegS-DegU regulating the synthesis of many secretory enzymes and being subject to sigma factor $\sigma^{\mathrm{A}}$ (Msadek et al., 1990) (right lower part in Fig. 1). In fact, the mutations in $\operatorname{deg} S$ and $\operatorname{deg} U$ lead to the overproduction of proteases (Msadek et al., 1990; Tanaka et al., 1991). Interestingly, special attention has been given to the role of DegU in the overproduction of $\alpha$-amylases in B. subtilis (Ploss et al., 2016). Also, the level of DegU-DegP was correlated with noisy transcription of subtilisin, aprE in B. subtilis (Veening et al., 2008).

\section{Sigma factor $\sigma^{B}$}

In $B$. subtilis, more than 40 genes belong to class II general stress genes, and sigma factor $\sigma^{\mathrm{B}}$-dependent promoters induce their expression in various conditions of stress (Hecker et al., 1996). Sigma factor $\sigma^{\mathrm{B}}$ is the first alternative sigma factor discovered in bacteria, and controls more than 150 genes (Hecker and Völker, 2001). These general stress proteins can protect non-growing cells by transforming them to be resistant to the damages from non-specific and multiple stresses, including acid, alkaline, heat, osmotic stress, or oxidative stress. Such an essential response to mild stresses may prevent cell death after future potentially lethal stress. Thus, the response of sigma factor $\sigma^{\mathrm{B}}$ is considered as a strategy of alternative survival, where the non-growing cell can stay in a vegetative state rather than sporulative state (Hecker and Völker, 2001). The main function of the $\sigma^{\mathrm{B}}$ regulon is protecting $B$. subtilis from reactive oxygen radicals. The activation of $\sigma^{\mathrm{B}}$-dependent transcription occurs during the stationary growth of $B$. subtilis cells or when they encounter some unfavorable environmental conditions, such as ethanol, heat shock, high salt, or $\mathrm{O}_{2}$ limitation (Haldenwang, 1995). The activity of sigma factor $\sigma^{\mathrm{B}}$ is controlled by RsbV-RsbW pathway, where RsbV is an antianti-sigma factor and binds to RsbW so sigma factor $\sigma^{\mathrm{B}}$ is activated (Alper et al., 1996). RsbW is an anti-sigma factor and binds to sigma factor $\sigma^{\mathrm{B}}$ to prevent the formation of holoenzyme E- $\sigma^{\mathrm{B}}$ (Bensom and Haldenwang, 1993), and RsbW is hypothesized to be sensitive to the ratio of ATP/ADP because ATP decrease can induce $\sigma^{\mathrm{B}}$ (Haldenwang, 1995).

\section{Sporulation-specific factors}

The sporulation in B. subtilis is characterized by cascades of gene expression that are regulated by sigma factors $\sigma^{\mathrm{E}}, \sigma^{\mathrm{F}}, \sigma^{\mathrm{G}}$, and $\sigma^{\mathrm{K}}$ (Stragier and Losick, 1990). Sigma factor $\sigma^{\mathrm{E}}$ plays an important role in B. subtilis sporulation (Feucht et al., 2003; Chary et al., 2005), and regulates the expression of many sporulation genes, such as SpoIIT (Meeske et al., 2016). The overproduction of $\alpha$-amylases can inhibit the sporulation in B. subtilis (Lulko et al., 2007) either by downregulating spo0A or by upregulating spoOJA and spoOE that negatively affect sporulation (Piggot and Hilbert, 2004). Indeed, sporulation can be initiated not only by starvation but also by various factors, including flagellar motility, production of antibiotics, secretion of proteases, heat stress, etc. (Meeske et al., 2016). An interesting question here is whether the induction of HtrA and HtrB synthesis provides the signal for the formation of heat-resistant spores? In order to prevent the formation of heat-resistant spores, the inhibition of sporulation happens (Lulko et al., 2007). SpoIIT functions directly in the cellcell signaling pathway that triggers proteolytic activation of sigma factor $\sigma^{\mathrm{E}}$ (Meeske et al., 2016). Initially, an inactive membrane-associated precursor pro- $\sigma^{\mathrm{E}}$ is synthesized (LaBell et al., 1987; Zhang et al., 1998), and then pro- $\sigma^{\mathrm{E}}$ undergoes a proteolytic process to become sigma factor $\sigma^{\mathrm{E}}$ (Fujita and Losick, 2002; Hofmeister, 1998).

In dormant spores of B. subtilis, there are 10 to $20 \%$ of the proteins belonging to small, acid-soluble spore proteins, and they are encoded by genes $s s p A$ to $s s p E$. One of the genes transcribed by E- $\sigma^{\mathrm{F}}$ is $g p r$ that encodes an endopeptidase to degrade small, acid-soluble spore proteins as a source of amino acids when spore germination occurs (Sussman and Setlow, 1991). SpoIIAA/SpoIIAB regulatory system determines when and where to activate sigma factor $\sigma^{\mathrm{F}}$. SpoIIAB preferentially binds to sigma factor $\sigma^{\mathrm{F}}$ when a cell has high ATP/ADP ratio, whereas SpoIIAB preferentially binds to SpoIIAA when a cell has low ATP/ADP ratio (Haldenwang, 1995). In the latter condition, SpoIIAB phosphorylates SpoIIAA, and thus inhibits the binding of SpoIIAA to SpoIIAB.

The holoenzyme $\mathrm{E}-\sigma^{\mathrm{G}}$ takes part in the transcription of sspE and gpr (Sussman and Setlow, 1991). In mutant B. subtilis, gpr transcription depends first on $\mathrm{E}-\sigma^{\mathrm{F}}$, and then on $\mathrm{E}-\sigma^{\mathrm{G}}$. In reality, gerA and gerD are a part of the $\sigma^{\mathrm{G}}$ regulon, indicating the involvement of sigma factor $\sigma^{\mathrm{G}}$ in germination of B. subtilis.

The synthesis of sigma factor $\sigma^{\mathrm{K}}$ in $B$. subtilis reveals more complicated regulation than that of other sigma factors (Haldenwang, 1995). Overexpression of cytoplasmic proteins could either have no effect on early sporulation gene expression (Jurgen et al., 2001) or have an effect on early sporulation gene expression (Lulko et al., 2007). The former suggests that the stress due to heterologous proteins rather than the stress due to overproduction would downregulate sporulation genes, whereas the latter suggests that both stresses play their role in early sporulation gene expression (Lulko et al., 2007). So our 
question raised here is which leads to the inhibition of sporulation, CssS or HtrA?

\section{The extracytoplasmic function family}

The extracytoplasmic function family belongs to group IV sigma factors, including $\sigma^{\mathrm{M}}, \sigma^{\mathrm{V}}, \sigma^{\mathrm{W}}, \sigma^{\mathrm{X}}, \sigma^{\mathrm{Y}}, \sigma^{\mathrm{Z}}$, and YlacZ (Helmann, 2002) in B. subtilis. They function with corresponding transmembrane anti-sigma to control some genes that relate to cell surface or transport (Gruber and Gross, 2003), so they regulate the integral response to cell envelope stresses and play roles to maintain homeostasis of the cell envelope (Helmann, 2016). Until now, there is lack of information on direct evidence between the group IV sigma factors and the overproduction of $\alpha$-amylases.

The review in this section explores the possibility that heterologous amylases are a stress to B. subtilis, and therefore, the synthesis of HtrA and HtrB before the secretion stress could be attributed to the general response operated by sigma factors in $B$. subtilis. In particular, sigma factors $\sigma^{\mathrm{A}}$ and $\sigma^{\mathrm{B}}$ could be responsible to the induction of HtrA and HtrB synthesis before the secretion stress, whereas sigma factors $\sigma^{\mathrm{E}}$, $\sigma^{\mathrm{F}}, \sigma^{\mathrm{G}}$, and $\sigma^{\mathrm{K}}$ could participate in the induction of HtrA and $\mathrm{HtrB}$ synthesis due to the overproduction of $\alpha$-amylases through a sporulation mechanism.

\section{Conclusions}

In this review, we analyze the literature to address the relationship between the secretion stress due to $\alpha$-amylases overproduction and the induction of HtrA and HtrB synthesis. The results shed light on understanding the discrepancy, i.e., in the common concept that the synthesis of proteases often occurs at the end of the exponential phase of growth in Bacillus, while most of protein secretion in B. subtilis occurs at the beginning of the stationary phase of growth.

The literature review supports the notion that the increase of $\mathrm{HtrA}$ and $\mathrm{HtrB}$ comes from the overproduction of $\alpha$-amylases through CssR-CssS regulatory pathway (Fig. 1). The literature review suggests that sigma factor $\sigma^{\mathrm{D}}$ also plays a role in the overproduction of $\alpha$-amylases that may be subpopulation dependent, and sigma factor $\sigma^{\mathrm{D}}$ may help to hold HtrA and HtrB back from massive secretion before the overproduction of $\alpha$-amylases (Fig. 2). The literature review implies that several sigma factors can promote the secretion of proteases at the end of the exponential phase of growth under the condition that heterologous amylases are considered as a stress.

Finally, it is curious why a cell must eliminate its secreted misfolded proteins in its extracellular space? In general, these secreted misfolded proteins are cut into pieces by secreted proteases, and then the fragments are taken into the cell. These fragments were supposed to facilitate efficient initiation of degradation by the proteases (Inobe and Matouschek, 2014; van der Lee et al., 2014). Does this suggest the lack of nutrients during the exponential phase for the cell? Furthermore, proteins with high degree of intrinsic disorder have a short cellular halflife (Tompa et al., 2008). How long is the half-life of $\alpha$ amylase in extracellular space? Nevertheless, the answers to these questions would be helpful for better operation of microbial cell factories.

Funding This study was partly supported by the National Natural Science Foundation of China Nos. 31460296, 21466007, and 31560315, Key Project of Guangxi Scientific Research and Technology Development Plan (AB17190534), Guangxi Science and Technology Development Project (14123001-6), and Special Funds for Building of Guangxi Talent Highland.

\section{Compliance with ethical standards}

Ethics approval and consent to participate Not applicable.

Consent for publication Both authors read and approved the manuscript.

Availability of data and material Not applicable.

Conflict of interest The authors declare that they have no conflict of interest.

Open Access This article is distributed under the terms of the Creative Commons Attribution 4.0 International License (http:// creativecommons.org/licenses/by/4.0/), which permits unrestricted use, distribution, and reproduction in any medium, provided you give appropriate credit to the original author(s) and the source, provide a link to the Creative Commons license, and indicate if changes were made.

\section{References}

Allmansberger R (1997) Temporal regulation of sigD from Bacillus subtilis depends on a minor promoter in front of the gene. $\mathrm{J}$ Bacteriol 179:6531-6535

Alper S, Dufour A, Garsin DA, Duncan L, Losick R (1996) Role of adenosine nucleotides in the regulation of a stressresponse transcription factor in Bacillus subtilis. J Mol Biol 260:165-177

Amati G, Bisicchia P, Galizzi A (2004) DegU-P represses expression of the motility fla-che operon in Bacillus subtilis. J Bacteriol 186: 6003-6014

Antelmann H, Darmon E, Noone D, Veening JW, Westers H, Bron S, Kuipers OP, Devine KM, Hecker M, van Dijl JM (2003) The extracellular proteome of Bacillus subtilis under secretion stress conditions. Mol Microbiol 49:143-156

Bensom AK, Haldenwang WG (1993) Bacillus subtilis ere is regulated by a binding protein (RsbW) that blocks its association with core RNA polymerase. Proc Natl Acad Sci U S A 90:2330-2334

Bertero MG, Gonzales B, Tarricone C, Ceciliani F, Galizzi A (1999) Overproduction and characterization of the Bacillus subtilis antisigma factor FlgM. J Biol Chem 274:12103-12107 
Bolhuis A, Broekhuizen CP, Sorokin A, van Roosmalen ML, Venema G, Bron S, Quax WJ, van Dijl JM (1998) SecDF of Bacillus subtilis, a molecular Siamese twin required for the efficient secretion of proteins. J Biol Chem 273:21217-21224

Caramori T, Barilla D, Nessi C, Sacchi L, Galizzi A (1996) Role of FlgM in sigma D-dependent gene expression in Bacillus subtilis. J Bacteriol 178:3113-3118

Chang BY, Chen KY, Wen YD, Liao CT (1994) The response of a Bacillus subtilis temperature-sensitive sigA mutant to heat stress. J Bacteriol 176:3102-3110

Chang Z (2016) The function of the DegP (HtrA) protein: protease versus chaperone. IUBMB Life 68:904-907

Chary VK, Meloni M, Hilbert DW, Piggot PJ (2005) Control of the expression and compartmentalization of (sigma)G activity during sporulation of Bacillus subtilis by regulators of (sigma)F and (sigma)E. J Bacteriol 187:6832-6840

Chen JB, Zhou YH, Zhao XY, Chen SW, Wei XT (2015) Comparative analysis on the effects of different host strains of Bacillus licheniformis on the expression and secretion of $\alpha$-amylase. Food Sci (Chinese) 36:196-200

Chen R, Guttenplan SB, Blair KM, Kearns DB (2008) Role of the sigma D-dependent autolysins in Bacillus subtilis population heterogeneity. J Bacteriol 191:5775-5784

Clausen T, Kaiser M, Huber R, Ehrmann M (2011) HTRA proteases: regulated proteolysis in protein quality control. Nat Rev Mol Cell Biol 12:152-162

Darmon E, Noone D, Masson A, Bron S, Kuipers OP, Devine KM, van Dijl JM (2002) A novel class of heat and secretion stress-responsive genes is controlled by the autoregulated CssRS two-component system of Bacillus subtilis. J Bacteriol 184:5661-5671

Daughdrill GW, Chadsey MS, Karlinsey JE, Hughes KT, Dahlquist FW (1997) The C-terminal half of the anti-sigma factor, FlgM, becomes structured when bound to its target, $\sigma 28$. Nat Struct Biol 4:285-291

Derré I, Rapoport G, Msadek T (1999) CtsR, a novel regulator of stress and heat shock response, controls clp and molecular chaperone gene expression in gram-positive bacteria. Mol Microbiol 31:117-131

Eichenberger P, Fujita M, Jensen ST, Conlon EM, Rudner DZ, Wang ST, Ferguson C, Haga K, Sato T, Liu JS, Losick R (2004) The program of gene transcription for a single differentiating cell type during sporulation in Bacillus subtilis. PLoS Biol 2:e328

Estacio W, Anna-arriola S, Adedipe M, Marquez-Magana LM (1998) Dual promoters are responsible for transcription initiation of the fla/che operon in Bacillus subtilis. J Bacteriol 180:3548-3555

Feucht A, Evans L, Errington J (2003) Identification of sporulation genes by genome-wide analysis of the sigmaE regulon of Bacillus subtilis. Microbiology 49(Pt 10):3023-3034

Figaj D, Gieldon A, Polit A, Sobiecka-Szkatula A, Koper T, Denkiewicz M, Banecki B, Lesner A, Ciarkowski J, Lipinska B, Skorko-Glonek J (2014) The LA loop as an important regulatory element of the HtrA (DegP) protease from Escherichia coli: structural and functional studies. J Biol Chem 289:15880-15893

Fujita M, Losick R (2002) An investigation into the compartmentalization of the sporulation transcription factor sigmaE in Bacillus subtilis. Mol Microbiol 43:27-38

Fujita M (2000) Temporal and selective association of multiple sigma factors with RNA polymerase during sporulation in Bacillus subtilis. Genes Cells 5:79-88

Ge X, Wang R, Ma J, Liu Y, Ezemaduka AN, Chen PR, Fu X, Chang Z (2014) DegP primarily functions as a protease for the biogenesis of $\beta$-barrel outer membrane proteins in the Gram-negative bacterium Escherichia coli. FEBS J 281:1226-1240

Gruber TM, Gross CA (2003) Multiple sigma subunits and the partitioning of bacterial transcription space. Annu Rev Microbiol $57: 441-466$
Gullón S, Vicente RL, Mellado RP (2012) A novel two-component system involved in secretion stress response in Streptomyces lividans. PLoS One 7:e48987

Haldenwang WG (1995) The sigma factors of Bacillus subtilis. Microbiol Rev 59:1-30

Hansen G, Hilgenfeld R (2013) Architecture and regulation of HtrAfamily proteins involved in protein quality control and stress response. Cell Mol Life Sci 70:761-775

Hecker M, Schumann W, Völker U (1996) Heat-shock and general stress response in Bacillus subtilis. Mol Microbiol 19:417-428

Hecker M, Völker U (2001) General stress response of Bacillus subtilis and other bacteria. Adv Microb Physiol 44:35-91

Hecker M, Völker U (1998) Non-specific, general and multiple stress resistance of growth-restricted Bacillus subtilis cells by the expression of the sigmaB regulon. Mol Microbiol 29:1129-1136

Helmann JD, Marquez LM, Chamberlin MJ (1988) Cloning, sequencing, and disruption of the Bacillus subtilis sigma 28 gene. J Bacteriol 170:1568-1574

Helmann JD (2016) Bacillus subtilis extracytoplasmic function (ECF) sigma factors and defense of the cell envelope. Curr Opin Microbiol 30:122-132

Helmann JD (2002) The extracytoplasmic function (ECF) sigma factors Adv Microb Physiol 46:47-110

Herbort M, Klein M, Manting EH, Driessen AJ, Freudl R (1999) Temporal expression of the Bacillus subtilis secA gene, encoding a central component of the preprotein translocase. J Bacteriol 181: 493-500

Hicks KA, Grossman AD (1996) Altering the level and regulation of the major sigma subunit of RNA polymerase affects gene expression and development in Bacillus subtilis. Mol Microbiol 20:201-212

Hofmeister A (1998) Activation of the proprotein transcription factor prosigmaE is associated with its progression through three patterns of subcellular localization during sporulation in Bacillus subtilis. J Bacteriol 180:2426-2433

Hsueh YH, Cozy LM, Sham LT, Calvo RA, Gutu AD, Winkler ME, Kearns DB (2011) DegU-phosphate activates expression of the anti-sigma factor FlgM in Bacillus subtilis. Mol Microbiol 81: $1092-1108$

Hyyryläinen HK, Bolhuis A, Darmon E, Muukkonen L, Koski P, Vitikainen M, Sarvas M, Prágai Z, Bron S, van Dijl JM, Kontinen VP (2001) A novel two-component regulatory system of Bacillus subtilis for the survival of severe secretion stress. Mol Microbiol 41: $1159-1172$

Inobe T, Matouschek A (2014) Paradigms of protein degradation by the proteasome. Curr Opin Struct Biol 24:156-164

Ju J, Mitchell T, Peters HIII, Haldenwang WG (1999) Sigma factor displacement from RNA polymerase during Bacillus subtilis sporulation. J Bacteriol 181:4969-4977

Jurgen B, Hanschke R, Sarvas M, Hecker M, Schweder T (2001) Proteome and transcriptome based analysis of Bacillus subtilis cells overproducing an insoluble heterologous protein. Appl Microbiol Biotechnol 55:326-332

Kashyap DR, Wang M, Liu LH, Boons GJ, Gupta D, Dziarski R (2011) Peptidoglycan recognition proteins kill bacteria by activating protein-sensing two-component systems. Nat Med 17:676-683

Kearns DB, Losick R (2005) Cell population heterogeneity during growth of Bacillus subtilis. Genes Dev 19:3083-3094

Kim DY, Kim KK (2002) Crystallization and preliminary X-ray studies of the protease domain of the heat-shock protein HtrA from Thermotoga maritima. Acta Crystallogr D Biol Crystallogr 58: $170-172$

Koper T, Polit A, Sobiecka-Szkatula A, Wegrzyn K, Scire A, Figaj D, Kadzinski L, Zarzecka U, Zurawa-Janicka D, Banecki B, Lesner A, Tanfani F, Lipinska B, Skorko-Glonek J (2015) Analysis of the link between the redox state and enzymatic activity of the HtrA (DegP) protein from Escherichia coli. PLoS One 10:e117413 
Krojer T, Garrido-Franco M, Huber R, Ehrmann M, Clausen T (2002) Crystal structure of DegP (HtrA) reveals a new protease-chaperone machine. Nature 28(416):455-459

Krojer T, Sawa J, Schäfer E, Saibil HR, Ehrmann M, Clausen T (2008) Structural basis for the regulated protease and chaperone function of DegP. Nature 453:885-890

Krüger E, Hecker M (1998) The first gene of the Bacillus subtilis clpC operon, ctsR, encodes a negative regulator of its own operon and other class III heat shock genes. J Bacteriol 180:6681-6688

LaBell TL, Trempy JE, Haldenwang WG (1987) Sporulation-specific sigma factor sigma 29 of Bacillus subtilis is synthesized from a precursor protein, P31. Proc Natl Acad Sci U S A 84:1784-1788

Liu G, Xing M, Yu SE (2005) High-effective expression of thermostable $\alpha$-amylase from a bacterial phage based recombinant Bacillus subtilis. China J Appl Environ Biol 11:368-372

Lord M, Barilla D, Yudkin MD (1999) Replacement of vegetative $\sigma$ A by sporulation-specific $\sigma \mathrm{F}$ as a component of the RNA polymerase holoenzyme in sporulating Bacillus subtilis. J Bacteriol 181:23462350

Löwer M, Weydig C, Metzler D, Reuter A, Starzinski-Powitz A, Wessler S, Schneider G (2008) Prediction of extracellular proteases of the human pathogen Helicobacter pylori reveals proteolytic activity of the Hp1018/19 protein HtrA. PLoS One 3:e3510

Lulko AT, Veening JW, Buist G, Smits WK, Blom EJ, Beekman AC, Bron S, Kuipers OP (2007) Production and secretion stress caused by overexpression of heterologous alpha-amylase leads to inhibition of sporulation and a prolonged motile phase in Bacillus subtilis. Appl Environ Microbiol 73:5354-5362

Margot P, Karamata D (1996) The wprA gene of Bacillus subtilis 168, expressed during exponential growth, encodes a cell-wall-associated protease. Microbiology 142:3437-3444

Margot P, Pagni M, Karamata D (1999) Bacillus subtilis 168 gene lytF encodes a gamma-D-glutamate-meso-diaminopimelate muropeptidase expressed by the alternative vegetative sigma factor, sigmaD. Microbiology 145:57-65

Marquez LM, Helmann JD, Ferrari E, Parker HM, Ordal GW, Chamberlin MJ (1990) Studies of sigma D-dependent functions in Bacillus subtilis. J Bacteriol 172:3435-3443

Meeske AJ, Rodrigues CD, Brady J, Lim HC, Bernhardt TG, Rudner DZ (2016) High-throughput genetic screens identify a large and diverse collection of new sporulation genes in Bacillus subtilis. PLoS Biol 14:e1002341

Mirel DB, Chamberlin MJ (1989) The Bacillus subtilis flagellin gene (hag) is transcribed by the sigma 28 form of RNA polymerase. $\mathrm{J}$ Bacteriol 171:3095-3101

Mirel DB, Estacio WF, Mathieu M, Olmsted E, Ramirez J, MarquezMagana LM (2000) Environmental regulation of Bacillus subtilis $\sigma^{\mathrm{D}}$-dependent gene expression. J Bacteriol 182:3055-3062

Mogk A, Homuth G, Scholz C, Kim L, Schmid FX, Schumann W (1997) The GroE chaperonin machine is a major modulator of the CIRCE heat shock regulon of Bacillus subtilis. EMBO J 16:4579-4590

Mogk A, Völker A, Engelmann S, Hecker M, Schumann W, Völker U (1998) Nonnative proteins induce expression of the Bacillus subtilis CIRCE regulon. J Bacteriol 180:2895-2900

Mordini S, Osera C, Marini S, Scavone F, Bellazzi R, Galizzzi A, Calvio C (2013) The role of SwrA, DegU and PD3 in fla/che expression in B. subtilis. PLoS One 8:e85065

Msadek T, Kunst F, Henner D, Klier A, Rapoport G, Dedonder R (1990) Signal transduction pathway controlling synthesis of a class of degradative enzymes in Bacillus subtilis: expression of the regulatory genes and analysis of mutations in $\operatorname{degS}$ and $\operatorname{deg} \mathrm{U} . \mathrm{J}$ Bacteriol 172: 824-834

Mukherjee S, Kearns DB (2014) The structure and regulation of flagella in Bacillus subtilis. Annu Rev Genet 48:319-340

Noone D, Howell A, Collery R, Devine KM (2001) YkdA and YvtA, HtrA-like serine proteases in Bacillus subtilis, engage in negative autoregulation and reciprocal cross-regulation of ykdA and yvtA gene expression. J Bacteriol 183:654-663

Noone D, Howell A, Devine KM (2000) Expression of ykdA, encoding a Bacillus subtilis homologue of HtrA, is heat shock inducible and negatively autoregulated. J Bacteriol 182:1592-1599

Ogura M, Tsukahara K (2012) SwrA regulates assembly of Bacillus subtilis DegU via its interaction with N-terminal domain of DegU. J Biochem 151:643-655

Pallen MJ, Wren BW (1997) The HtrA family of serine proteases. Mol Microbiol 26:209-221

Piggot PJ, Hilbert DW (2004) Sporulation of Bacillus subtilis. Curr Opin Microbiol 7:579-586

Ploss TN, Reilman E, Monteferrante CG, Denham EL, Piersma S, Lingner A, Vehmaanperä J, Lorenz P, van Dijl JM (2016) Homogeneity and heterogeneity in amylase production by Bacillus subtilis under different growth conditions. Microb Cell Factories 15: 57

Priest FG (1977) Extracellular enzyme synthesis in the genus Bacillus. Bacteriol Rev 41:711-753

Shen WF, Niu BL, Weng HB, He LH, Meng ZQ (2005) The studies on Bacillus subtilis as an expression system of foreign genes. Acta Agriculturae Zhejiangensis 17:234-238

Shorenstein RG, Losick R (1973) Purification and properties of the sigma subunit of ribonucleic acid polymerase from vegetative Bacillus subtilis. J Biol Chem 248:6163-6169

Singh N, Kuppili RR, Bose K (2011) The structural basis of mode of activation and functional diversity: a case study with HtrA family of serine proteases. Arch Biochem Biophys 516:85-96

Skorko-Glonek J, Sobiecka-Szkatula A, Lipinska B (2006) Characterization of disulfide exchange between DsbA and HtrA proteins from Escherichia coli. Acta Biochim Pol 53:585-589

Sorenson MK, Ray SS, Darst SA (2004) Crystal structure of the flagellar $\sigma /$ anti- $\sigma$ complex $\sigma 28 / \mathrm{FlgM}$ reveals an intact $\sigma$ factor in an inactive conformation. Mol Cell 14:127-138

Spiess C, Beil A, Ehrmann M (1999) A temperature-dependent switch from chaperone to protease in a widely conserved heat shock protein. Cell 97:339-347

Stragier P, Losick R (1990) Cascades of sigma factors revisited. Mol Microbiol 4:1801-1806

Sussman MD, Setlow P (1991) Cloning, nucleotide sequence, and regulation of the Bacillus subtilis gpr gene, which codes for the protease that initiates degradation of small, acid-soluble proteins during spore germination. J Bacteriol 173:291-300

Tanaka T, Kawata M, Mukai K (1991) Altered phosphorylation of Bacillus subtilis DegU caused by single amino acid changes in DegS. J Bacteriol 173:5507-5515

Tjalsma H, Bolhuis A, Jongbloed JD, Bron S, van Dijl JM (2000) Signal peptide-dependent protein transport in Bacillus subtilis: a genomebased survey of the secretome. Microbiol Mol Biol Rev 64:515-547

Tompa P, Prilusky J, Silman I, Sussman JL (2008) Structural disorder serves as a weak signal for intracellular protein degradation. Proteins 71:903-909

Tsukahara K, Ogura M (2008) Promoter selectivity of the Bacillus subtilis response regulator DegU, a positive regulator of the fla/che operon and sacB. BMC Microbiol 8:8

van der Lee R, Lang B, Kruse K, Gsponer J, Sánchez de Groot N, Huynen MA, Matouschek A, Fuxreiter M, Babu MM (2014) Intrinsically disordered segments affect protein half-life in the cell and during evolution. Cell Rep 8:1832-1844

Vande Walle L, Lamkanfi M, Vandenabeele P (2008) The mitochondrial serine protease HtrA2/Omi: an overview. Cell Death Differ 15(3): 453-460

Veening JW, Igoshin OA, Eijlander RT, Nijland R, Hamoen LW, Kuipers $\mathrm{O}$ (2008) Transient heterogeneity in extracellular protease production by Bacillus subtilis. Mol Syst Biol 4:184 
Vicente RL, Gullón S, Marín S, Mellado RP (2016) The three Streptomyces lividans HtrA-like proteases involved in the secretion stress response act in a cooperative manner. PLoS One 11:e 0168112

Wegele H, Müller L, Buchner J (2004) Hsp70 and Hsp90 - a relay team for protein folding. Rev Physiol Biochem Pharmacol 151:1-44

Wei X, Zhou Y, Chen J, Cai D, Wang D, Qi G, Chen S (2015) Efficient expression of nattokinase in Bacillus licheniformis: host strain construction and signal peptide optimization. J Ind Microbiol Biotechnol 42:287-295

Westers H, Westers L, Darmon E, van Dijl JM, Quax WJ, Zanen G (2006) The CssRS two-component regulatory system controls a general secretion stress response in Bacillus subtilis. FEBS J 273:3816-3827

Yamamoto H, Miyake Y, Hisaoka M, Kurosawa S, Sekiguchi J (2008) The major and minor wall teichoic acids prevent the sidewall local- ization of vegetative DL-endopeptidase LytF in Bacillus subtilis. Mol Microbiol 70:297-310

Yan S, Wu G (2017) Bottleneck in secretion of $\alpha$-amylase in Bacillus subtilis. Microb Cell Factories 16:124

Zhang B, Hofmeister A, Kroos L (1998) The prosequence of pro-sigmaK promotes membrane association and inhibits RNA polymerase core binding. J Bacteriol 180:2434-2441

Zuber U, Schumann W (1994) CIRCE, a novel heat shock element involved in regulation of the heat shock operon dnak of Bacillus subtilis. J Bacteriol 176:1359-1363

Publisher's note Springer Nature remains neutral with regard to jurisdictional claims in published maps and institutional affiliations. 